\title{
"Evaluación de la ansiedad y depresión en los pacientes con insuficiencia renal cronica en hemodiálisis durante un año"
}

\author{
Laura Giera Vives, Ana Rico González
}

\section{Centros Concertados. Asyter Cuenca y Asyter Albacete}

\section{Introducción:}

Los pacientes en hemodiálisis tienen que pasar por un proceso de adaptación, en el cual uno de los elementos más importantes son las emociones. El paciente se enfrenta a situaciones nuevas, aumentando el riesgo de presentar depresión o ansiedad. Al ser una enfermedad crónica, se necesita un trabajo interdisciplinario de médicos, psicólogos, enfermeras, etc. El apoyo familiar y social también es un factor importante a tener en cuenta en el tratamiento de la ansiedad y la depresión.

\section{Objetivo:}

Evaluar los cambios que se producen en ansiedad y depresión durante un año en los pacientes con insuficiencia renal crónica (IRC) en hemodiálisis (HD) y así poder implantar un tratamiento adecuado para mejorar los síntomas de las posibles alteraciones psicológicas que puedan aparecer.

\section{Material y métodos:}

Se trata de un estudio descriptivo observacional de corte transversal, realizado en los pacientes de dos centros concertados de hemodiálisis. Se excluyeron los pacientes con trastornos sensitivos, cognitivos y/o psiquiátricos severos que imposibilitaron la realización de los cuestionarios. Fueron incluidos un total de 98 pacientes, 63 varones y 35 mujeres, con una edad de 68,11 $\pm 13,35$ (27-87) años, que disponían de dos evaluaciones anuales consecutivas. Para evaluar el nivel de ansiedad utilizamos el Cuestionario de Ansiedad Estado-Rasgo, STAI (C.D. Spielberger, R.L. Gorsuch y R.E. Lushene). Para el nivel de depresión la adapta- ción española del Inventario de Depresión Estado-Rasgo, IDER (G. Buela-Casal, D.Agudelo Vélez). Las entrevistas para los cuestionarios se realizaron entre febrero 2012 y marzo 2013. Análisis estadístico con el paquete Spss v.11.0 Las variables se describen como media \pm desviacion típica (rango). Para la comparación de medias entre las dos evaluaciones se utilizó la Prueba T de student.

\section{Resultados:}

En la primera evaluación en el percentil 75 o por encima, están en depresión-estado el 77,55 \% de pacientes y en depresión-rasgo el $76,53 \%$, y en la segunda evaluación el 73,47 \% y 59,18 \% respectivamente. La disminución en la puntuación de depresión-rasgo entre la primera y la segunda evaluación es estadísticamente significativa $(p<0,001)$. La ansiedad es menos frecuente con decatipo $\geq 7$, en ansiedad-estado el $24,49 \%$ de pacientes y en ansiedad-rasgo el $38,78 \%$ en la primera evaluación, y en la segunda evaluación el 19,39 \% y el $30,61 \%$ respectivamente. Las diferencias en la puntuación de ansiedad entre la primera y segunda evaluación no llegan a ser estadísticamente significativa.

\section{Conclusiones:}

La mayoría de los pacientes presentan depresión. La prevalencia de depresión en pacientes en programa de hemodiálisis es más elevada que la de ansiedad. Enfermería es la que pasa más tiempo con los pacientes por lo tanto sería interesante elaborar un plan de acción para trabajar en equipo y que así los pacientes puedan disminuir sus síntomas emocionales cuando están en diálisis. 


\section{Referencias Bibliográficas}

1. Valdés, C. et al. Análisis del acuerdo entre la valoración que hacen los pacientes en hemodiálisis de su Calidad de Vida Relacionada con la Salud (CVRS) y la valoración que de ellos hace el personal de enfermería. Rev. Soc. Esp. Enferm. Nefrol 2010; 13 (4): 228,233.

2. Ruiz de Alegría, B. et al. Cambios en las estrategias de afrontamiento en los pacientes de diálisis a lo largo del tiempo. Rev. Soc. Esp. Enferm. Nefrol 2009; 12 (1): 11/17.

3. Miguel, M., Valdés, C., Rábano, M., Artos, Y., Cabello, P., de Castro, N., García A., Martínez, A., Ortega, F. Variables asociadas a la satisfacción del paciente en una unidad de hemodiálisis. Rev. Soc. Esp. Enferm. Nefrol 2009;12(1): 19/25.

4. Ugalde, M. Enfermería de salud mental y psiquiátrica. Masson, 2006.
5. Moreno, E. et al. Estudio de la prevalencia de trastornos ansiosos y depresivos en pacientes en hemodiálisis. Rev. Soc. Esp. Enferm. Nefrol. 2004; 7 (4): $225 / 233$.

6. Páez A. E. et al. (2009). Ansiedad y depresión en pacientes con Insuficiencia Renal Crónica en tratamiento de diálisis. Universitas Psicológica, 8(1), 117-124.

7. Moreno, E., Arenas, M.D., Porta, E., Escalant, L., Cant, M.J, F.et al. (2004). Estudio de la prevalencia de trastornos ansiosos y depresivos en pacientes en hemodiálisis. Revista de la Sociedad Española de Enfermería Nefrológica, 4(7) 17-25.

8. Álvarez, F., Fernández, M., Vázquez ,A. M.J., Mon, C., Sánchez, R.\& Rebollo, P (2001). Síntomas físi$\cos$ y Trastornos emocionales en pacientes en programa de Hemodiálisis periódica. Nefrología, 21 (2), 191-199. 